\title{
Briggsia hastingi, a new genus and species of clingfish from Oman
}

\author{
MATTHEW T. CRAIG ${ }^{1} \&$ JOHN E. RANDALL ${ }^{2}$ \\ ${ }^{1}$ University of Puerto Rico, Mayagüez, P.O. Box 9000, Mayagüez, PR 00683 \\ ${ }^{2}$ Bishop Museum, 1525 Bernice Street, Honolulu, HI 96817
}

\begin{abstract}
Briggsia hastingsi is described as a new genus and species of gobiesocid fish from a single specimen, $22 \mathrm{~mm}$ in standard length, collected in $2 \mathrm{~m}$ depth on the southeastern coast of Oman. The genus differs principally from other aspasmine genera in having fewer dorsal- and anal-fin rays (4 each) and a shorter head (head length 2.5 in standard length).
\end{abstract}

Key words: Gobiesocidae, Aspasminae, Briggsia, Oman

\section{Introduction}

The clingfish family Gobiesocidae is well named for the ability of the species to attach firmly to the substratum with a thoracic sucking disc, developed partly from modified pelvic fins of one small spine and four soft rays. All the species have a single posterior dorsal fin without spines, an anal fin without spines, broad pectoral fins with 16-31 rays, no scales, no swim bladder, usually a broad head, and a slender tapering body. A skin toxin was reported for two species (Hori et al., 1979). The family is represented in all tropical to warm temperate seas, and some species are found in fresh water. Many occur in shallow water, often in areas of high surge because of their adhering capability; many are cryptic, hiding beneath stones or among algae, and some species are commensal with invertebrates. Briggs (1955) revised the family, which he divided into eight subfamilies, characterized principally by the number of gill arches, whether the gill membranes are attached to the isthmus, and whether the thoracic disc is double or single. He recognized 33 genera and 93 species. There are now 35 genera and 156 species in the family (Eschmeyer \& Fricke, 2009).

A small specimen of an unidentified clingfish was collected in $2 \mathrm{~m}$ depth at Raha Bay $\left(16^{\circ} 57^{\circ} \mathrm{N}, 54^{\circ} 49^{\prime} \mathrm{E}\right)$ on the southeastern coast of Oman in 1993, and a color photograph was taken by the second author. No additional specimens are known. The specimen has 3 instead of $31 / 2$ gill arches, the gill membranes attached to the isthmus, and it has a double thoracic disc; therefore it is classified in the subfamily Aspasminae. It is distinct from the genera of this subfamily, as defined by Briggs (1955). We describe it here as a new genus and species.

\section{Materials and methods}

The following measurements were taken of the holotype with digital calipers and recorded to the nearest 0.01 $\mathrm{mm}$ (Table 1): standard length (SL) from the median anterior end of the upper lip to the posterior end of the hypural plate (base of caudal fin); body depth from the origin of pelvic fins, and body width from the origin of the pectoral fins; head length (HL) was taken from the upper lip to the posterior end of the opercular membrane; orbit diameter is the greatest fleshy diameter, and the interorbital width the least bony width; snout length was measured from the median anterior point of the upper lip to the nearest fleshy edge of the orbit; 
upper-jaw length from the same anterior point to the posterior end of the maxilla; caudal-peduncle depth is the least depth, and caudal-peduncle length the horizontal distance between verticals at the rear base of the anal fin and the caudal-fin base. Postdorsal-caudal distance is measured from the base of the dorsal-fin origin to the midbase of the caudal fin. Counting gill-rakers required enlarging the gill cavity; following Briggs, they were counted on the second and third arches. Fin rays were counted from x-rays. Principal caudal rays, as defined by Briggs, are those with free tips (we note also that these articulate with the hypural plate).

\section{Briggsia, new genus}

Type species: Briggsia hastingsi, new species

Diagnosis: A monotypic genus of Aspasminae with no prominent vertical ridges on side of body; head large, its length 2.5 in SL; head width 3.9 in SL; body depth 6.1 in SL; disc double and moderately large, 3.9 in SL; dorsal and anal fins small, posterior on body, each with 4 rays; pectoral rays 23; gill rakers on second arch 9 , on third arch 10; vertebrae 29.

Description: As given below for the only known species.

Etymology: Briggsia is named in honor of Dr. John C. Briggs, in recognition of his major contributions to clingfish systematics.

\section{Briggsia hastingsi, new species}

Figures 1-3; Table 1

Holotype: BPBM 36539, 22 mm SL, Oman, southeastern coast, Rahah Bay, $16^{\circ} 57^{\circ} \mathrm{N}, 54^{\circ} 49^{\prime} \mathrm{E}, 2 \mathrm{~m}$, quinaldine, John P. Hoover, 8 February 1993.

Diagnosis: A species of aspasimine gobiesocid with dorsal and anal fins posterior on body, each with 4 rays; pectoral rays 23; caudal fin broad and rounded, with 10 principal rays; gill rakers on first gill arch 9, on third arch 10; head large, its length 2.5 in SL; body depth 6.1 in SL; disc double and well-separated; disc length 3.9 in SL; disc width 4.4 in SL; color in alcohol uniform tan; color when fresh dark reddish gray with numerous blue dots on side of body except posteriorly, and a few on postorbital head; a dark purplish brown stripe from front of snout, continuing posterior to eye; head ventral to stripe yellowish white; a distinct orange ring around pupil.

Description: Dorsal rays 4; anal rays 4; pectoral rays 23; principal caudal rays 10; upper procurrent caudal rays 6; lower procurrent caudal rays 5; gill rakers on second gill arch 9; gill rakers on third gill arch 10; vertebrae 29.

Body depth 6.1 in SL; body rounded anteriorly, progressively more compressed posteriorly; head length 2.5 in SL; head width 2.5 in SL; snout length 2.6 in HL; eye diameter 6.35 in HL; caudal-peduncle depth 1.1 in its length.

Disc double, well-separated, and of moderate size; disc length 3.9 in SL; disc width 4.4 in SL; anus about half way between origin of anal fin and posterior edge of disc. Disc region "A" (sensu Briggs, 1955) with several rows of flattened papillae; disc region "B" with three rows of flattened papillae; disc region "C" with four rows of flattened papillae; a small, oval region slightly posterior to disc region "A" with two circular pads formed by flattened papillae (Fig. 2)

Mouth slightly inferior, oblique, and moderately large, the upper-jaw length 6.3 in SL; front of jaws with a sandpaper-like pad of small teeth, followed by two or three well-developed canines and two rows of incisors.

Nostrils well separated and distinctly tubular; five pairs of cephalic sensory pores; nasal sensory canals 2, postorbital canals 1 , lachrymal canals 2 (Fig. 3).

Origins of dorsal and anal fins in vertical alignment; postdorsal-caudal distance 8.3 in SL; dorsal-caudal 
distance 5.3 in SL; no fleshy pad at base of pectoral fin.

Color of holotype in alcohol uniform tan. Color when fresh: body and dorsal part of head reddish gray; numerous blue dots on side of body except posteriorly; a few blue dots on postorbital head; a dark purplish brown stripe from upper lip to eye, continuing obliquely downward a short distance behind eye; head below stripe abruptly yellowish white; a short blue line at ventral edge of dark stripe posterior to eye; eye colored like adjacent head except for a bright orange ring around pupil; dorsal and anal fins translucent with vague pale spots; caudal fin with reddish rays and clear membranes, the upper and lower rays with a row of pale spots; paired fins pale.

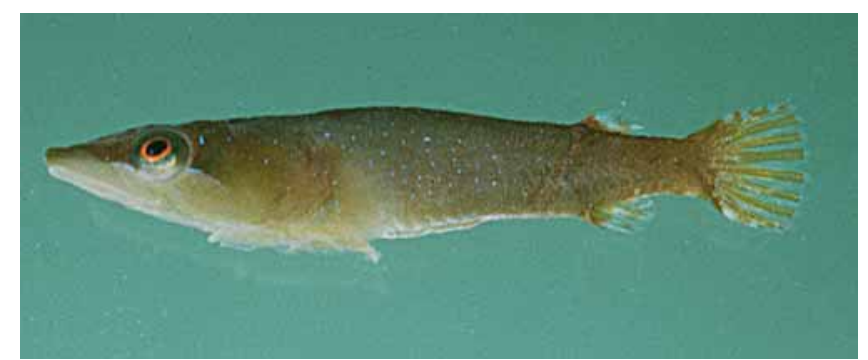

FIGURE 1. Holotype of Briggsia hastingsi, BPBM 36539, 22 mm SL, Oman (Photo: J.E. Randall).

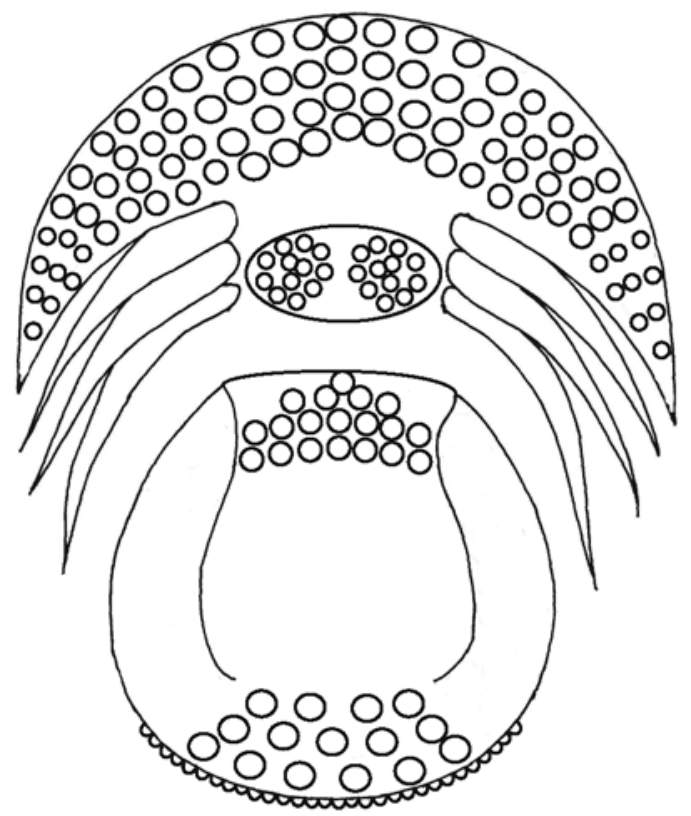

FIGURE 2. Disc of holotype of Briggsia hastingsi (M.T. Craig).

Etymology: This species name hastingsi is named in honor of Dr. Philip A. Hastings, the thesis advisor of the first author, who initially aroused the first author's curiosity in clingfishes.

Remarks: Randall (1996) published a book entitled Coastal Fishes of Oman. Fish collections for this volume include a single specimen of a clingfish taken in 1993 that he was unable to identify to genus or species. We are aware of no additional material of this species, which is so distinctive that we no longer hesitate to describe it from a single specimen.

Shiogaki \& Dotsu (1983) reported on the head sensory canal pores of the Gobieosocidae and proposed that the orientation and number of these pores may be useful to differentiate clingfish genera. The pattern observed in B. hastingsi (nasal canals 2, postorbital canals 1, lachrymal canals 2) would indicate a close relationship with species of the genera Pherallodus and Parvicrepis of the subfamily Diplocrepinae. Species of the Diplocrepinae, however, have gill membranes that are free from the isthmus, thus $B$. hastingsi with its 
attached gill membranes is placed in the Aspaminae, following Briggs (1955). Briggs (1993) described a new genus and species, Posidonichthys hutchinsi, which also possesses three gills, a double disc, and gill membranes that are attached to the isthmus, indicating its placement within the Aspasminae. However, Briggs noted several characters in the general osteology of $P$. hutchinsi that suggest a close relationship to the Diplocrepinae. The relationship of these two subfamilies is in need of further study.

TABLE 1. Proportional Measurements of the holotype of Briggsia hastingsi as percentages of the standard length.

\begin{tabular}{ll}
\hline Standard Length $(22 \mathrm{~mm})$ & - \\
\hline Body Depth & 6.1 \\
Body Width & 4.6 \\
Head Length & 2.5 \\
Head Width & 3.9 \\
Snout Length & 6.5 \\
Orbit Diameter & 16.0 \\
Interorbital Width & 13.9 \\
Upper-jaw Length & 6.3 \\
Caudal-peduncle Depth & 16.0 \\
Caudal-peduncle Length & 13.9 \\
Predorsal Length & 1.2 \\
Preanal Length & 1.3 \\
Longest Dorsal-fin Ray & 18.9 \\
Longest Anal-fin Ray & 20.8 \\
Caudal-fin Length & 7.7 \\
Pectoral-fin Length & 10.4 \\
Dorsal-caudal Distance & 5.3 \\
Postdorsal-caudal Distance & 8.3 \\
Disc Length & 3.9 \\
Disc Width & 4.4 \\
\hline
\end{tabular}
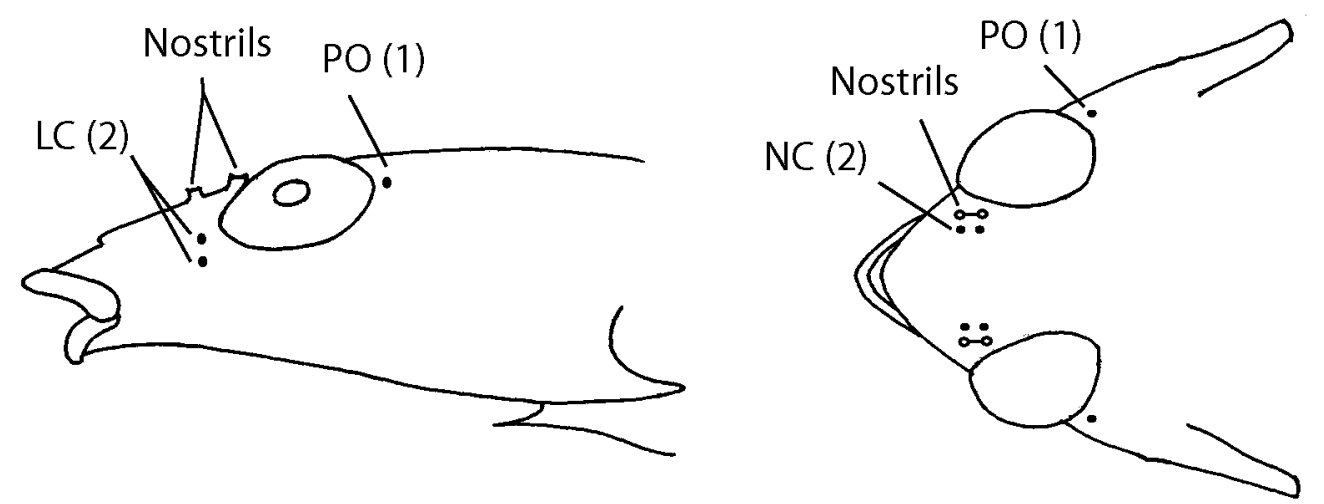

FIGURE 3. Cephalic sensory pores of holotype of Briggsia hastingsi (M.T Craig, following Briggs, 1993). PO—Post orbital canals, LC-Lachrymal canals, NC—Nasal canals.

\section{Acknowledgements}

We thank John P. Hoover for collecting the holotype of B. hastingsi (he was with the second author in Oman), 
Sergey Bogorodsky for bringing the specimen to our attention, Loreen R. O'Hara and Arnold Y. Suzumoto of the Bishop Museum for curatorial assistance, and Richard Pyle for assistance with photographic editing. We also thank John C. Briggs and an unidentified reviewer for helpful comments on the manuscript.

\section{References}

Briggs, J.C. (1955) A monograph of the clingfishes (Order Xenopterygii). Stanford Ichthyological Bulletin 6, iv +224 pp.

Briggs, J.C. (1993) New genus and species of clingfish (Gobiesocidae) from southern Australia. Copeia, 1993(1), 196199.

Eschmeyer, W.N. \& Fricke, R. (2009) Catalog of Fishes electronic version (updated 13 Mar. 2009). http:// research.calacademy.org/ichthyology/catalog/fishcatsearch.html.

Hori, K., Fusetani, N., Hashimoto, K., Aida, K. \& Randall, J.E. (1979). Occurrence of a grammistin-like mucous toxin in the clingfish Diademichthys lineatus. Toxicon, 17, 418-424.

Randall, J.E. (1996). Coastal Fishes of Oman. University of Hawaii Press, Honolulu. xiii + 432 pp.

Shiogaki, M. \& Y. Dotsu (1983) Two new genera and two new species of clingfishes from Japan with comments on head sensory canals of the Gobiesocidae. Japanese Journal of Ichthyology, 30, 111-121 